\title{
Estimating Flood Quantiles on the Basis of Multi-Event Rainfall Simulation - Case Study
}

\author{
Elżbieta JAROSIŃSKA ${ }^{1}$ and Katarzyna PIERZGA ${ }^{2}$ \\ ${ }^{1}$ Institute of Water Engineering and Water Management, \\ Cracow University of Technology, Cracow, Poland; \\ e-mail: ejarosin3@gmail.com (corresponding author) \\ ${ }^{2}$ Hydromodel Center of Hydrologic and Environmental Engineering, \\ Brzezna, Poland; e-mail: katarzyna.pierzga@hydromodel.pl
}

\begin{abstract}
This paper presents an approach to estimating the probability distribution of annual discharges $Q$ based on rainfall-runoff modelling using multiple rainfall events. The approach is based on the prior knowledge about the probability distribution of annual maximum daily totals of rainfall $P$ in a natural catchment, random disaggregation of the totals into hourly values, and rainfall-runoff modelling. The presented Multi-Event Simulation of Extreme Flood method (MESEF) combines design event method based on single-rainfall event modelling, and continuous simulation method used for estimating the maximum discharges of a given exceedance probability using rainfall-runoff models. In the paper, the flood quantiles were estimated using the MESEF method, and then compared to the flood quantiles estimated using classical statistical method based on observed data.
\end{abstract}

Key words: rainfall event, precipitation generating, rainfall-runoff modelling, probability distribution of annual maximum discharges, antecedent runoff conditions, flood quantiles. 


\section{INTRODUCTION}

It is projected that climate changes (SPA 2020 (2013)) and inconsistent system of urban planning (including accelerated catchment sealing process) (KPZK 2030 (2013)) will have a significant impact on causing negative changes in water regime in Poland until 2030. According to Kowalczak (2011), it is changes in land use (land sealing) that should be seen as the major cause of floods, while the changing climate will contribute to changing the precipitation character. Forecasts estimate that despite almost unchanged annual precipitation total, the character of this phenomenon will become more random and heavy rainfalls (above $20 \mathrm{~mm}$ /day) will likely become noticeable, especially in the southern part of Poland.

Seeing how these reasons pose challenges that demand appropriate methods of engineering hydrology, the authors undertook to analyse a new approach to estimating probability distribution of maximum annual discharges. This approach makes it possible to consider future changes in urban planning of a catchment as well as consider the changeable character of precipitation. Both of these phenomena have a significant impact on the increase in maximum discharge and the change in their probability distribution.

The presented method is based on the information about probability distribution of maximum daily rainfall totals in catchment, their random distribution into hourly values (disaggregation), and multi-event rainfall-runoff modelling. It also involves considering different moisture conditions of the soil in the catchment, because catchment moisture condition before the rainfall event resulting in a flood wave is essential for the discharge values (Pathiraja et al 2012).

The method combines the design event method based on single event modelling (Pilgrim and Cordery 1993) and the continuous simulation method (Boughton and Droop 2003, Calver and Lamb 1995), both used for estimating probable maximum discharges with the application of rainfall-runoff models. For brevity, the new method is called Multi-Event Simulation of Extreme Flood (MESEF).

The design event method assumes that the estimation of a flood of selected exceedance probability results from a design rainfall of the same exceedance probability. A hyetograph is used as the input data for the rainfall-runoff model, with the precipitation duration equal to (or greater than) the time of concentration in the catchment (DVWK 1984) and usually with a method of disaggregation into smaller time steps.

The major advantage of the design event method lies in its simplicity of use and easiness in interpreting results. On the other hand, many of its elements raise questions. It is debatable, for instance, what rainfall duration 
should be considered - whether it should be equal to or greater than concentration time (DVWK 1984), whether over 8.5 hours (Nowicka et al. 1997) or 24 hours (USDA 1986). Also, the issue of establishing the antecedent runoff conditions in the catchment has not been definitely resolved; at present, average conditions are assumed or maximum catchment saturation prior the rainfall event is implied. A similar simplification is used in relation to temporal distribution of rainfall; it is common to apply fixed temporal distributions (4 types) (USDA 1986), or a distribution with a peak in the middle of a rainfall event (DVWK 1984), or to simply search for a distribution that will generate the maximum runoff (Banasik 2009).

The second method - the continuous simulation method - requires a stochastic rainfall generator. The generated continuous rainfall sequences provide input for the continuous rainfall-runoff model (Cameron et al. 1999). Continuous sequences of modelled runoff are then obtained, and their maximum values (as in the case of the observed data) are subjected to statistical analysis to identify the probability distribution and calculate quantile values.

Considering the application of rainfall-runoff models for estimating quantile values of probable maximum discharges, the design event method is a classical approach. At the same time, the continuous simulation method is recognized as its practical alternative.

So far, the continuous simulation method has not been used in Poland in practical application, although there have been first attempts to use it for designing a storm drain system (Licznar 2009). It is worth noting that this method eliminates most of the disadvantages of the design event method. What is more, Pathiraja et al. (2012) observed its superiority in considering catchment moisture condition in modelling, which is important on account that underestimating its correct simulation could result in underestimating discharge peak values. Boughton and Droop (2003) pointed out the possibility to eliminate the necessity to match the duration and rainfall time distribution in modelling, which raises many questions and concerns in the design event method. However, the rainfall-runoff models used in this method are more complex, i.e., they have more parameters, and hence the calibration of these models is more difficult. It is also essential that a stochastic rainfall generator with parameters adjusted to the local conditions be used in the method, because it allows for generation of long synthetic rainfall series.

Alongside the application of both methods separately, there have also been approaches combining them both, e.g., SCHADEX (Paquet et al. 2013), or other described by Francés et al. (2008), as well as applications related to the use of the Monte Carlo method for multidimensional probability distributions (Rahman et al. 2002). The SCHADEX method uses an approach described as semi-continuous. A continuous rainfall-runoff model (MORDOR) is used along with rainfall data from multiannual period whose 
fragments are substituted with synthetic rainfall events. This approach makes it possible to obtain the probability distribution of maximum discharges without making assumptions about the condition of the catchment prior to the rainfall - the condition results from a real historical period. SCHADEX method was applied in Poland for the first time by Osuch et al. (2013), using the Nysa Kłodzka catchment as a case study. Somewhat different solutions are proposed in the approach presented by Francés et al. (2008). Their methodology implies identifying annual discharges $Q$ on the basis of modelling of nonrandomized synthetic rainfall events for different known moisture conditions.

The present study evaluates whether the MESEF method could be used to receive the probability distribution of maximum discharges on the basis of multi-event rainfall simulation. In order to prove the validity of the proposed method, the quantiles received from the MESEF were compared with the quantiles received from the classical statistical method.

\section{STUDY AREA}

The MESEF method was applied in the Czarny River catchment, situated in south-eastern Poland with the area of $95.2 \mathrm{~km}^{2}$ to the Polana gauge (Fig. 1). The elevation differences in the catchment reach $600 \mathrm{~m}$. The drainage system is very well developed, and its density reaches almost $3 \mathrm{~km} / \mathrm{km}^{2}$. Over $80 \%$ of this catchment is forestland.

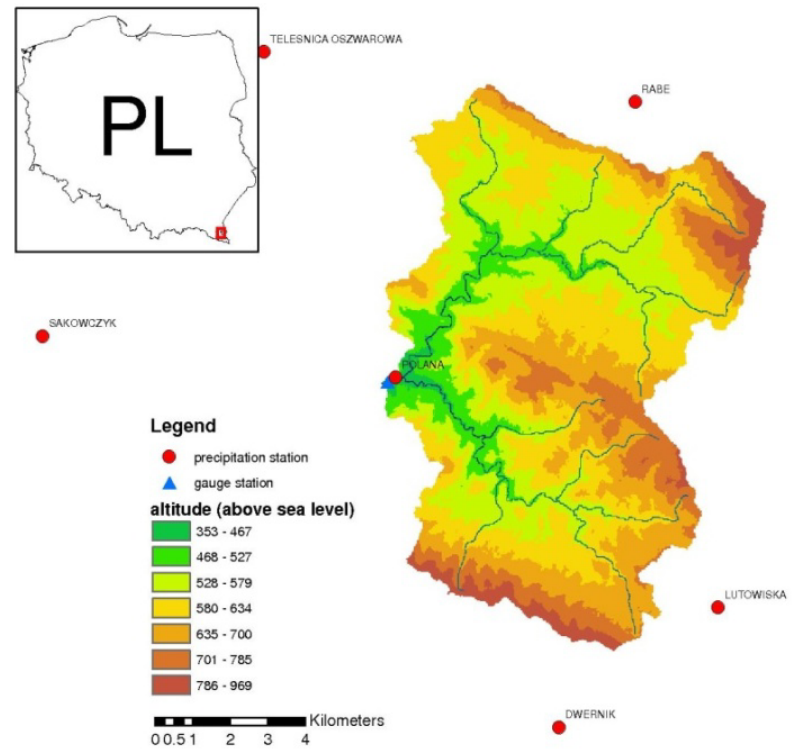
- suposian tions.
Fig. 1. The Czarny River catchment with the network of precipitation sta- 
Sequence of annual maximum daily rainfall totals $P_{o}$ and annual discharges $Q_{o}$ from a 36-year period (1977-2012) from the Polana precipitation and Polana gauge stations, respectively, were chosen for analyses. A simplifying assumption was made that the data from the Polana station are equivalent to the areal precipitation of the entire catchment.

The Czarny catchment planning did not change in a significant way throughout the period from which the data in the article was sourced. In other words, the catchment retained its natural character thanks to which the land use changes did not affect the discharge values, and, in consequence, could be chosen as representative for the purposes of the article. This particular catchment is therefore a solid starting point for analyzing the influence of catchment planning changes on changes in discharge maximum values.

\section{MESEF - ASSUMPTIONS AND STAGES}

The MESEF method is based on the assumption that rainfall-runoff modelling replicated for multiple rainfall events, originating from the probability distribution of annual maximum daily rainfall totals $P_{o}$, will make it possible to obtain the probability distribution of annual maximum discharges $Q_{o}$. This distribution is developed on the basis of peak discharge values obtained from modelling. An assumption was also made about rainfall disaggregation: in order to break down the maximum daily precipitation into hourly values, beta probability distribution function, with parameters $\alpha$ and $\beta$, was used. The values of these parameters were generated from a known twodimensional distribution of $\alpha$ and $\beta$ based on measurement data. The MESEF method assumes conducting rainfall-runoff modelling for three types of antecedent runoff conditions (ARC) in the catchment: dry, normal, and wet (Hawkins et al. 2009).

The MESEF method is conducted in three stages.

a Rainfall generation:

- identification of the probability distribution of observed $P_{o}$,

- generating synthetic values of $P_{s}$ from the identified probability distribution,

- generating pairs of parameters $\alpha$ and $\beta$ from their two-dimensional frequency distribution,

- creating hyetographs with an hourly time step by disaggregation of synthetic $P_{s}$;

\ Rainfall-runoff modelling:

- identification of parameters of the selected model on the basis of physiographic characteristics of the catchment,

- calibration of the model for the assumed ARC in the catchment,

- creating synthetic runoff hydrographs on the basis of rainfall hyetographs for three kinds of ARC by modelling; 
- Estimating probability distributions of synthetic $Q_{s}$ for the best proportion $\mathrm{ARC}$, description of the procedure of finding the best proportion ARC in Section 6:

- estimating the flood quantiles.

The following chapters contain detailed description of the work carried out during the specific stages of the MESEF.

\section{RAINFALL GENERATION}

In general, synthetic hyetographs are generated by a rainfall generator. In order to generate a hyetograph, it is necessary to provide annual maximum daily rainfall totals and the $\alpha$ and $\beta$ parameters of the beta distribution. The proposed MESEF method requires an analysis of many rainfall events (many hyetographs). This is why synthetic daily totals generation from the probability distribution of observed $P_{o}$ was used, as well as generation of the beta distribution parameters $\alpha$ and $\beta$ from their two-dimensional frequency distribution.

It was assumed that the observed annual maximum daily rainfall totals $P_{o}$ have the three-parameter Weibull distribution $\mathrm{W}(\lambda, \kappa, \gamma)$ (Fig. 2), where $\lambda$, $\kappa>0$ and the density function was expressed by the following formula 1 :

$$
f_{w}\left(p_{0}, \lambda, \kappa, \gamma\right)=\left\{\begin{array}{c}
\frac{\kappa}{\lambda}\left(\frac{p_{0}-\gamma}{\lambda}\right)^{\kappa-1} \exp \left(-\left(\frac{p_{0}-\gamma}{\lambda}\right)^{\kappa}\right) \text { for } p_{0} \geq \gamma . \\
0 \text { for } p_{0}<\gamma
\end{array}\right.
$$

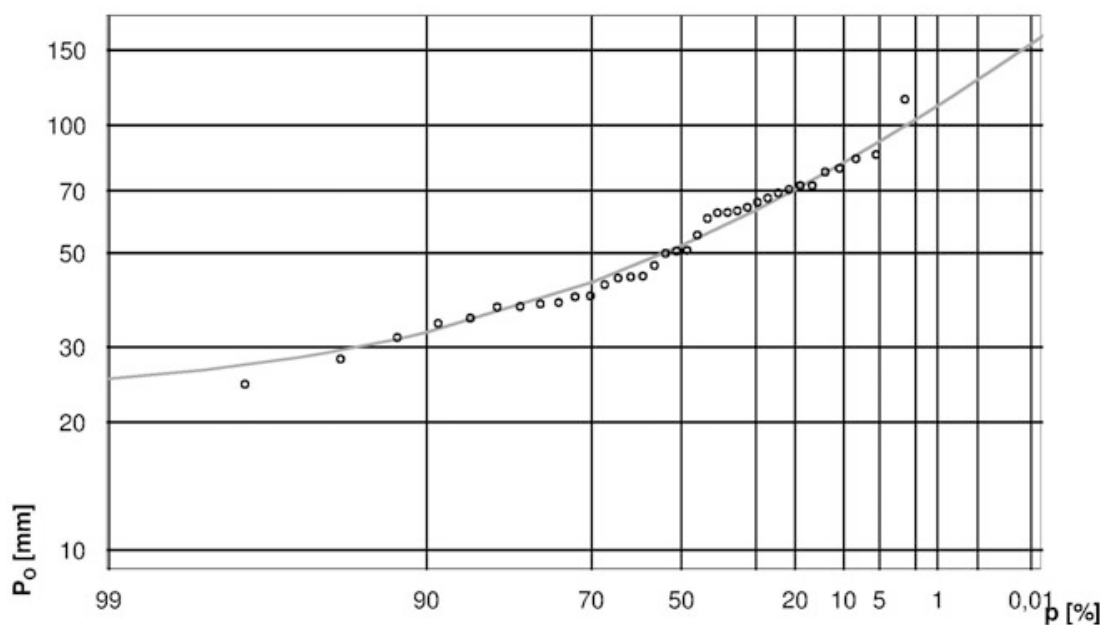

Fig. 2. Empirical (circles) and theoretical (solid line) probability exceedance function of $P_{o}$ from the 36-year period (1977-2012) from the Polana precipitation station (Weibull distribution $\lambda=1.7107, \kappa=36.137, \gamma=22.827$ ). 
The parameters of this distribution were estimated using the maximum likelihood method.

The description of the generator's operation was based on the example of generating 100-element rainfall sample. From the Weibull distribution, 100 synthetic $P_{s}$ values were generated. In order to estimate the uncertainty related to generating precipitation, there were ten 100 -element samples generated from Weibull distribution. All of the generated samples underwent Pearson goodness-of-fit test $\chi^{2}\left(\chi^{2} \mathrm{P}\right)$ with Weibull theoretical distribution. None of the samples was rejected by that test at the level of significance alpha $=0.05$, even though the test statistics differed. Finally, in order to limit the uncertainty of the MESEF method, it was assumed that the best input for the rainfall-runoff model will be the sample whose test statistics had the lowest value, in other words - the one that performed best in $\chi^{2}$ test. It can be expected that greater number of generated precipitation samples will allow choosing the best of them, i.e. closest to the theoretical distribution.

Each of 100 synthetic $P_{s}$ values was broken down into hourly values using density function $f_{B}(y ; \alpha, \beta)$ and the method of generating $\alpha$ and $\beta$ parameters of the beta distribution $\operatorname{Be}(\alpha, \beta)$, where $\alpha, \beta>0$, and the density function was expressed using the following formula 2 :

$$
f_{B}(y, \alpha, \beta)=\left\{\begin{array}{c}
\frac{1}{B(\alpha, \beta)} y^{\alpha-1}(1-y)^{\beta-1} \quad \text { for } y \in(0,1) \\
0 \text { for } y \notin(0,1)
\end{array},\right.
$$

where $B(\alpha, \beta)$ is the beta function.

The properties of this distribution, i.e., the arbitrary asymmetry (dependent on the values of the parameters $\alpha$ and $\beta$ ) and its double-sided limitation make it applicable in the distribution of the daily precipitation into the values for smaller time steps (Więzik 2010).

Because $\alpha$ and $\beta$ parameters have an influence on how the rainfall totals are broken down into hourly values (Fig. 3), information was searched for concerning the possible values of these parameters.

In the end, the range and the frequency of occurrence of the values of $\alpha$ and $\beta$ parameters of the beta distribution $\operatorname{Be}(\alpha, \beta)$ were used. These were obtained by fitting beta distribution to daily precipitation broken down into hourly values, based on the multiannual period of 1961-1985 for Cracow, with an assumption that the data used are representative of catchments in the Carpathian region. Making such an assumption, the authors are aware that it may cause a kind of bias in generating $\alpha$ and $\beta$ parameters of the beta distribution $\operatorname{Be}(\alpha, \beta)$; however, only these data with a one-hour step were available for their calculations. 
(a)

(b)
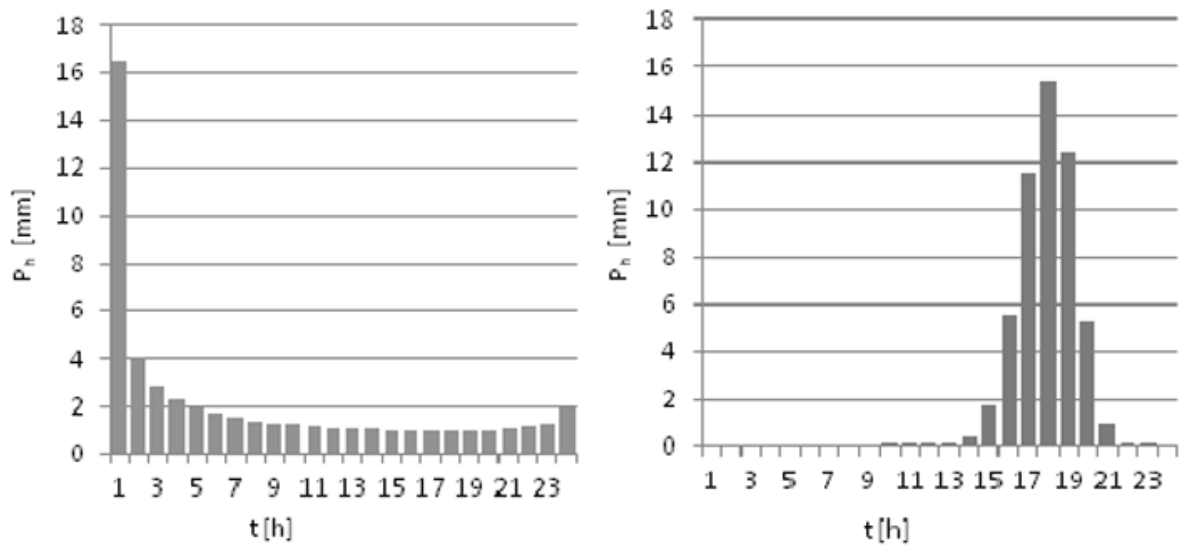

(c)

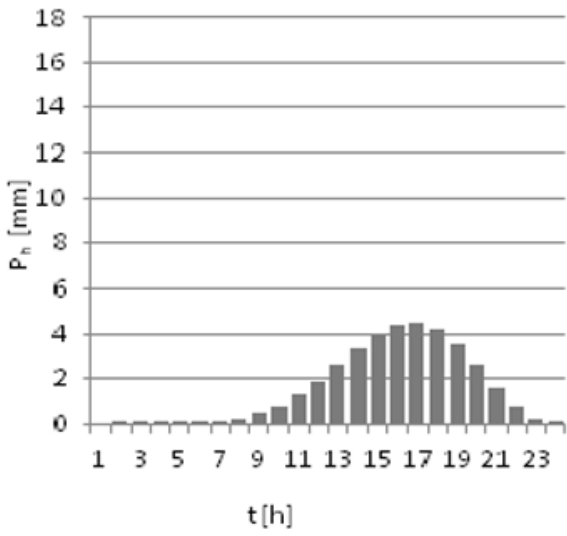

Fig. 3. Exemplary hyetographs of annual maximum daily rainfall totals: (a) $P=51.2 \mathrm{~mm}$, (b) $P=53.4 \mathrm{~mm}$, (c) $P=36.7 \mathrm{~mm}$, broken down into 24 hourly values, for which the values of the beta parameters $(\alpha, \beta)$ are: (a) $\alpha=0.313$, $\beta=0.725$, (b) $\alpha=45.391, \beta=17.131$, and (c) $\alpha=8.251, \beta=4.418$.

Only rainfalls with at least $10 \mathrm{~mm}$ daily total were used for the calculations. As a result, 274 pairs of parameters $(\alpha, \beta)$ were obtained with values ranging from 0 to 60 (Table 1 ).

In order to generate values of the parameter pairs $(\alpha, \beta)$, a two-dimentional distribution of the frequency of occurrence was used in accordance with Table 1 . Generating of pairs $(\alpha, \beta)$ should be performed in three stages: i.e., firstly an interval $\Delta \alpha_{i}$ from the marginal distribution of $\alpha$ is generated, then $\Delta \beta_{j}$ from the conditional probability distribution $P\left(\beta \in \Delta \beta_{j} \mid \alpha \in \Delta \alpha_{i}\right)$, and then, independently of each other, $\alpha$ and $\beta$ from the uniform distribution 


\section{Table 1}

Frequency of parameters $(\alpha, \beta)$ occurrence of the beta distribution in the $(0,60) \times(0,60)$ domain*)

\begin{tabular}{|c|c|c|c|c|c|c|c|c|c|c|c|c|c|c|c|c|c|}
\hline & \multicolumn{14}{|c|}{$\beta$} & \multirow{2}{*}{\multicolumn{2}{|c|}{ Total }} \\
\hline & & \multicolumn{2}{|c|}{$(0,1)$} & \multicolumn{2}{|c|}{$[1,2)$} & \multicolumn{2}{|c|}{$[2,5)$} & \multicolumn{2}{|c|}{$[5,10)$} & \multicolumn{2}{|c|}{$[10,20)$} & \multicolumn{2}{|c|}{$[20,30)$} & \multicolumn{2}{|c|}{$[30,60)$} & & \\
\hline & & a.f. & \begin{tabular}{|l} 
r.f. \\
{$[\%]$}
\end{tabular} & a.f. & $\begin{array}{l}\text { r.f. } \\
{[\%]}\end{array}$ & a.f. & \begin{tabular}{|c|} 
r.f. \\
{$[\%]$}
\end{tabular} & a.f. & \begin{tabular}{|c|} 
r.f. \\
{$[\%]$}
\end{tabular} & a.f. & \begin{tabular}{|c|} 
r.f. \\
{$[\%]$} \\
\end{tabular} & a.f. & \begin{tabular}{|l|} 
r.f. \\
{$[\%]$} \\
\end{tabular} & a.f. & \begin{tabular}{|l|} 
r.f. \\
{$[\%]$} \\
\end{tabular} & a.f. & \begin{tabular}{|c} 
r.f. \\
{$[\%]$} \\
\end{tabular} \\
\hline & $(0,1)$ & 18 & 6.6 & 7 & 2.6 & 6 & 2.2 & 0 & 0 & 0 & 0 & 0 & 0 & 0 & 0 & 31 & 11.3 \\
\hline & {$[1,2)$} & 2 & 0.7 & 14 & 5.1 & 13 & 4.7 & 5 & 1.8 & 0 & 0 & 1 & 0.4 & 0 & 0 & 35 & 12.8 \\
\hline & {$[2,5)$} & 3 & 1.1 & 7 & 2.6 & 17 & 6.2 & 12 & 4.4 & 6 & 2.2 & 2 & 0.7 & 2 & 0.7 & 49 & 17.9 \\
\hline$a$ & {$[5,10)$} & 1 & 0.4 & 11 & 4.0 & 9 & 3.3 & 7 & 2.6 & 5 & 1.8 & 1 & 0.4 & 4 & 1.5 & 38 & 13.9 \\
\hline & {$[10,20)$} & 0 & 0 & 2 & 0.7 & 7 & 2.6 & 6 & 2.2 & 9 & 3.3 & 7 & 2.6 & 3 & 1.1 & 34 & 12.4 \\
\hline & {$[20,30)$} & 0 & 0 & 0 & 0 & 2 & 0.7 & 7 & 2.6 & 19 & 6.9 & 19 & 6.9 & 3 & 1.1 & 50 & 18.2 \\
\hline & {$[30,60)$} & 0 & 0 & 0 & 0 & 1 & 0.4 & 3 & 1.1 & 27 & 9.9 & 6 & 2.2 & 0 & 0 & 37 & 13.5 \\
\hline & Total & 24 & 8.8 & 41 & 15.0 & 55 & 20.1 & 40 & 14.6 & 66 & 24.1 & 36 & 13.1 & 12 & 4.4 & 274 & 100 \\
\hline
\end{tabular}

*) The calculations were performed in 2013 by Stanisław Węglarczyk, Cracow University of Technology, Institute of Water Engineering and Water Management.

Explanations: a.f. - absolute frequency, r.f. - relative frequency.

(a)

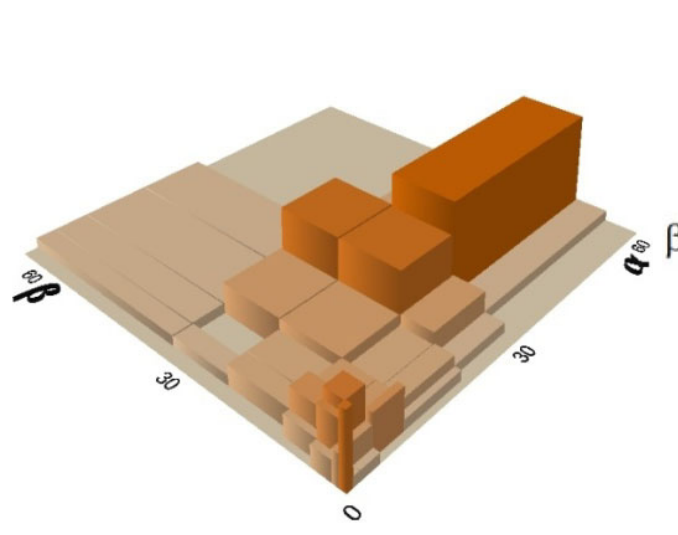

(b)

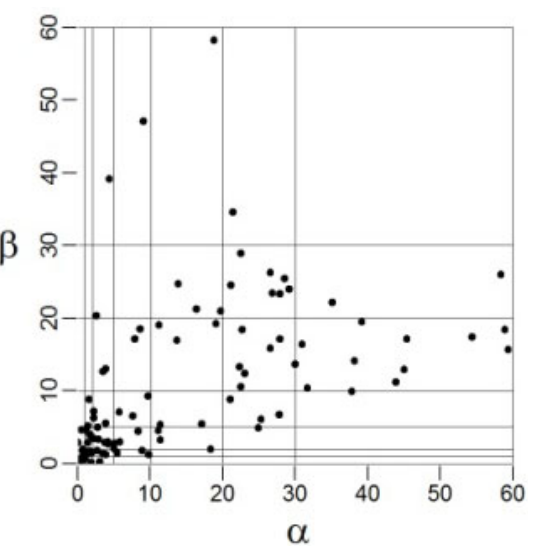

Fig. 4. Two-dimentional distribution of parameters $\alpha$ and $\beta$ : (a) 2D histogram of $(\alpha, \beta)$ values in the $(0,60) \times(0,60)$ domain based on calculations by Stanisław Węglarczyk, and (b) generated 100 pairs of $(\alpha, \beta)$ parameters used in that work.

of the appropriate intervals $\Delta \alpha_{i}$ and $\Delta \beta_{j}$. This, in practice, comes down to generating 100 pairs of parameters $(\alpha, \beta)$ from the areas marked out by the occurrence interval boundaries of parameters $\alpha$ and $\beta$ (Fig. 4). 


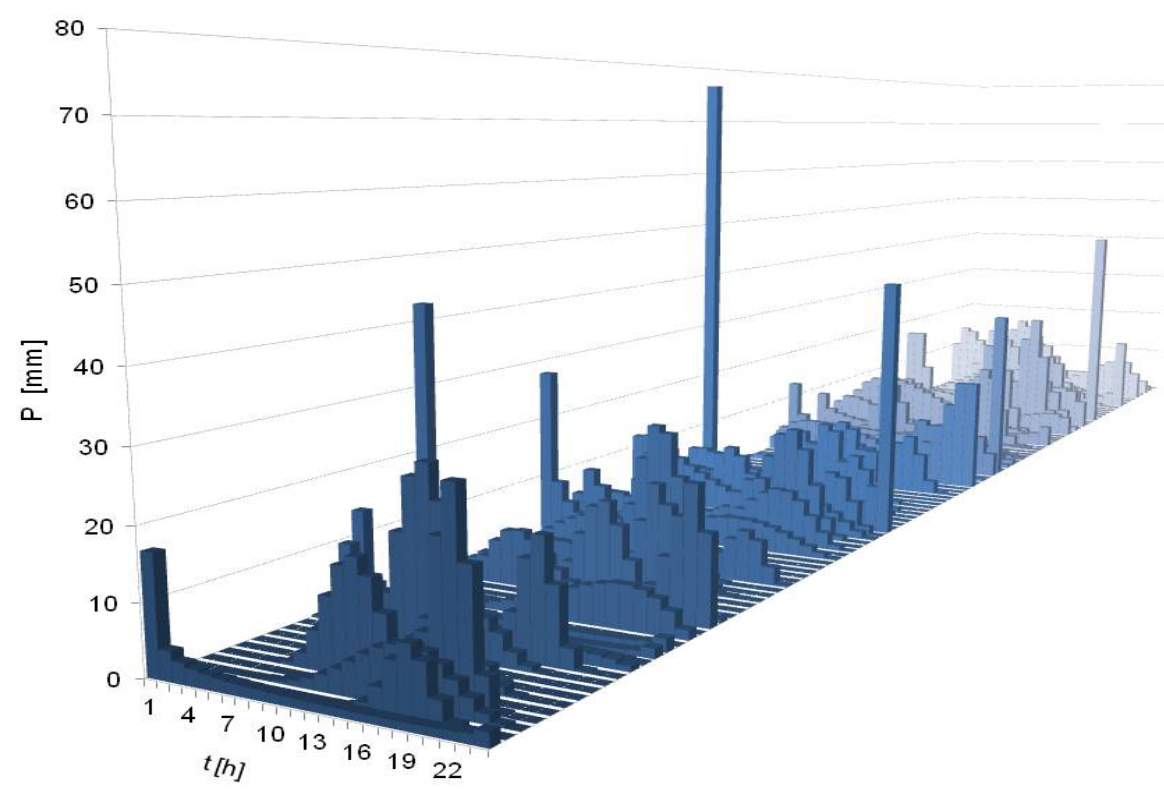

Fig. 5. Exemplary generated hyetographs.

Parameters $\alpha$ and $\beta$ are independent of the daily rainfall totals. This means that since there was no correlation found either between parameter $\alpha$ and daily totals of rainfall $P$, or parameter $\beta$ and daily totals of rainfall $P$, parameters $\alpha$ and $\beta$ can be generated independently of synthetic $P_{s}$ generation.

Using the beta density function $f_{B}(y ; \alpha, \beta)$ for disaggregation of synthetic $P_{s}$ for hourly values $P_{h}$ allowed for 100 rainfall hyetographs to be obtained (Fig. 5), and they constitute the input data for the rainfall-runoff model. It means that only one pair $(\alpha, \beta)$ was applied to every generated rainfall total.

\section{RAINFALL-RUNOFF MODEL}

Version 3.5 of the Hydrologic Engineering Center Hydrologic Modeling System (HEC-HMS) (Scharffenberg and Fleming 2010) was used for modelling the runoff from the investigated catchment.

The Soil Conservation Service (now the Natural Resources Conservation Service) Curve Number loss method (SCS CN), based on the knowledge of total precipitation, soil type, land cover type, and soil moisture at the beginning of the rainfall, was used to determine the value of effective rainfall. All of these factors are taken into account in the $\mathrm{CN}$ parameter (Mishra and Singh 2003). The Unit Hydrograph method (SCS UH), used to determine the value of the peak discharge, total runoff volume, hydrograph shape, and time history, was chosen for the rainfall-runoff transformation. To determine the 
baseflow, the Recession Method was used. It allows the approximation of a typical streamflow behaviour also after the rainfall event. This situation - the descending part of the hydrograph - is depicted in the form of an exponential recession curve (Scharffenberg and Fleming 2010).

The choice of these simple methods was driven by their widespread use, small number of parameters, as well as their applicability in ungauged catchments due to the possibility of parameter estimation on the basis of catchment characteristics. Moreover, the loss and transformation models allow to diversify the parameter values of the HEC-HMS model according to the catchment antecedent runoff conditions which have an influence on the values of peak discharges. This is significant for the MESEF method proposed in this paper.

Data from three flood hydrographs from 1997, 2007, and 2008 were used for calibration and verification of the model parameters. The data included precipitation from the Polana station and discharges from the Polana gauge on the Czarny River. The calibration procedure was conducted using HECHMS software. Five parameters from the model underwent calibration: the initial abstraction, $\mathrm{CN}$ parameter, $T_{\mathrm{Lag}}$ parameter, baseflow threshold coefficient, and recession constant. Different ARC which had impact on the value of the $\mathrm{CN}$ parameter and the value of the dependent $T_{\text {Lag }}$ parameter were allowed for in the calibration procedure. During this procedure, it has been observed that sensitivity of SCS CN loss model for changes of an initial abstraction is not as significant as in the case of other models (Lee and Huang 2013).

In order to assess the quality of the chosen rainfall-runoff model, a direct comparison between the observed and simulated peak discharges was carried out (Table 2). The values of relative errors show at least good quality of the model and this is why it could be used for generating synthetic discharge hydrographs.

Table 2

Comparison between the observed and simulated peak discharges

\begin{tabular}{|c|c|c|c|}
\hline Year & $\begin{array}{c}\text { Observed peak discharges } \\
{\left[\mathrm{m}^{3} / \mathrm{s}\right]}\end{array}$ & $\begin{array}{c}\text { Simulated peak discharges } \\
{\left[\mathrm{m}^{3} / \mathrm{s}\right]}\end{array}$ & $\begin{array}{c}\text { Relative error } \\
{[\%]}\end{array}$ \\
\hline 1997 & 111.0 & 107.61 & 3.1 \\
2007 & 63.4 & 54.89 & 13.4 \\
2008 & 111.0 & 115.12 & 3.7 \\
\hline
\end{tabular}

Rainfall-runoff modelling was conducted for a set of generated rainfall events, for three kinds of antecedent runoff conditions (ARC) in the catchment: dry (ARC I), normal (ARC II), and wet (ARC III) (Fig. 6). 
(a)

(b)
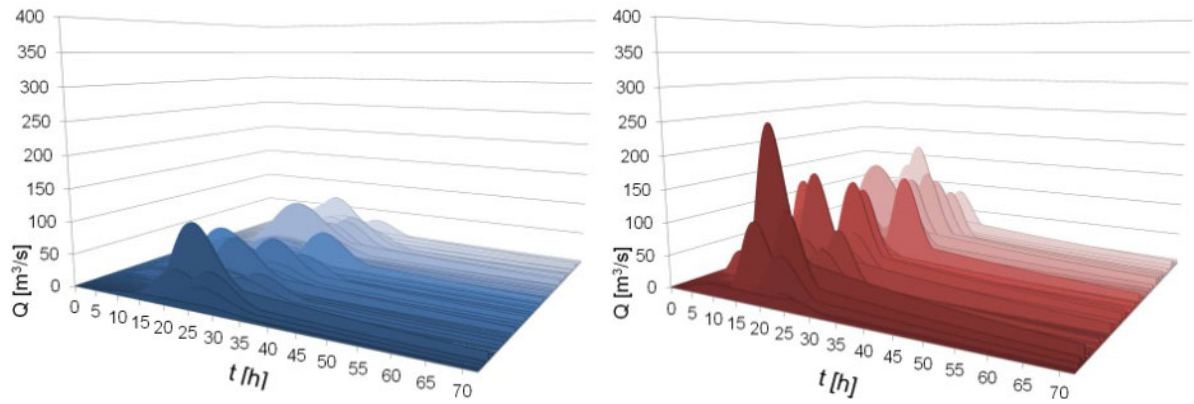

(c)

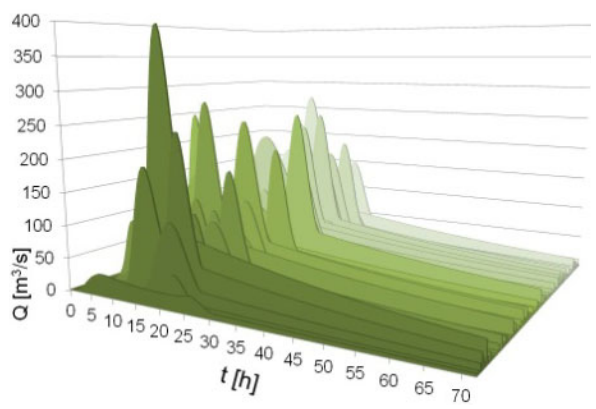

Fig. 6. Exemplary discharge hydrographs for a set of 100 synthetic rainfall events for ARC: (a) dry ARC I, (b) normal ARC II, (c) wet ARC III.

\section{FINDING THE BEST PROPORTION OF ARC FOR SYNTHETIC PEAK DISCHARGE VALUES $\boldsymbol{Q}_{S}$}

According to Hawkins et al. (2009), the absolute average conditions ARC may be variable depending on factors such as local climate, soil, vegetation, and land use. This is the purpose behind finding the most frequently occurring runoff conditions. In the case of the Czarny catchment, these conditions were searched for by means of estimating the best proportion of antecedent runoff conditions ARC for 100 synthetic rainfall events.

The analyses performed in this part of the work were supposed to answer the question about the conditions required to be fulfilled by the synthetic data $Q_{s}$ to identify the probability distribution of observed $Q_{o}$. It was assumed that the probability distribution of observed $Q_{o}$ was the actual distribution, and attempts were made to make the synthetic data yield the best possible fit to that distribution, including events with a very small exceedance probability.

\subsection{Estimation of the probability distribution of $Q_{o}$}

From among several analysed probability distributions (Węglarczyk 2010, Stedinger et al. 1993), i.e., the two-parameter gamma, Gumbel (Fisher- 
Tippett type I), Weibull (Fisher-Tippett type III), GEV, and log-normal, the two-parameter log-normal distribution demonstrated the best fit to the observations $Q_{o}$ (Table 3, Fig. 7). The density function of the log-normal distribution $\operatorname{LN}(\mu, \sigma)$, where $\mu, \sigma>0$, was expressed by the following formula 3 :

$$
f\left(q_{0}, \mu, \sigma\right)\left\{\begin{array}{c}
\frac{1}{q_{0} \sigma \sqrt{2 \pi}} \exp \left[-\frac{\left(\ln \left(q_{0}\right)-\mu\right)^{2}}{2 \sigma^{2}}\right] \text { for } q_{0}>0 . \\
0 \text { for } q_{0} \leq 0
\end{array} .\right.
$$

The parameters of this distribution were estimated using the maximum likelihood method.

Table 3

Statistic values of the Kolmogorov-Smirnov goodness-of-fit test for examined probability distributions for observed $Q_{o}$ from the 36-year period (1977-2012) from the Polana gauge*

\begin{tabular}{|c|c|c|c|c|c|}
\hline \multirow{2}{*}{$\begin{array}{l}\text { Probability } \\
\text { distribution }\end{array}$} & \multicolumn{2}{|c|}{ Kolmogorov-Smirnov } & \multirow{2}{*}{$\begin{array}{l}\text { Sample } \\
\text { size }\end{array}$} & \multicolumn{2}{|c|}{$\begin{array}{c}\text { Critical value at } \\
\text { the alpha level of significance }\end{array}$} \\
\hline & $\begin{array}{l}\text { Statistic } \\
\text { value }\end{array}$ & Rank & & alpha $=0.2$ & alpha $=0.1$ \\
\hline $\begin{array}{c}\text { log-normal } \\
\text { (two-parameter) }\end{array}$ & 0.0756 & 1 & 36 & 0.1742 & 0.1991 \\
\hline $\begin{array}{c}\text { GEV } \\
\text { gamma } \\
\text { Weibull } \\
\text { Gumbel max }\end{array}$ & $\begin{array}{l}0.0795 \\
0.0868 \\
0.0937 \\
0.1152\end{array}$ & $\begin{array}{l}2 \\
3 \\
4 \\
5\end{array}$ & & & \\
\hline
\end{tabular}

*) Source of data: Institute of Meteorology and Water Management, Polish National Research Institute.

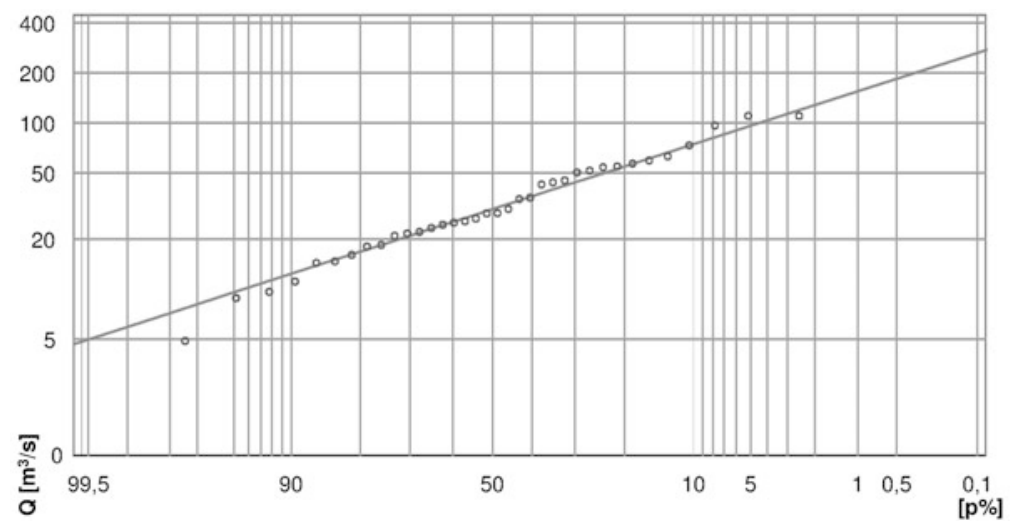

Fig. 7. Empirical (circles) and theoretical (solid line) probability exceedance function of $Q_{o}$ from the 36-year period (1977-2012) from the Polana gauge (log-normal distribution: $\mu=3.4149, \sigma=0.71172$ ). 


\subsection{Creating combinations $Q_{\text {sci }}$ of synthetic peak discharge values $Q_{s}$ for different ARC}

In order to create combinations $Q_{\text {sci }}$ sequences of synthetic peak discharge values $Q_{s}$ for three kinds of ARC were used. 300 synthetic peak discharge values $Q_{s}$ were read off from the 300 synthetic hydrographs (Fig. 5), i.e., 100 values for each of the three kinds of ARC (Fig. 8), namely $Q_{s_{-} \text {I }} Q_{s_{-} \text {II }}$, and $Q_{s_{-} \text {III. }}$

In the next stage, the combinations $Q_{\text {sci }}(i=1, \ldots, 38)$ of the values of $Q_{s_{-} \text {I }}, Q_{s_{-} \text {III }}$, and $Q_{s_{-} \text {III }}$ were created to find the best fit between the probability distribution of the combination $Q_{\text {sci }}$ and the theoretical probability distribution of the observed $Q_{o}$ data.

For this purpose, an appropriate number of values was generated from each of the $Q_{s_{-} \text {I, }} Q_{s_{-} \text {II }}$, and $Q_{s_{-} \text {III }}$ sets, creating - as a result - new 100 -element series of randomly intermixed discharge values for different ARC. Generating was performed for 38 possible combinations, creating thirty-eight 100element discharge series. Thus, the combination 2-0-1 indicates, for example, that from $Q_{s_{-} I} 67$ values were generated, which accounts for $2 / 3$ of the elements of the entire series, while from $Q_{s_{\text {III }}} 33$ values were generated, which accounts for the remaining $1 / 3$ of the elements of the entire series. In this case no discharge value was generated from $Q_{s_{\text {III }}}$. It means that this combination was affected by dry ( $2 / 3$ of all values) and wet ( $1 / 3$ of all values) runoff conditions in the catchment.

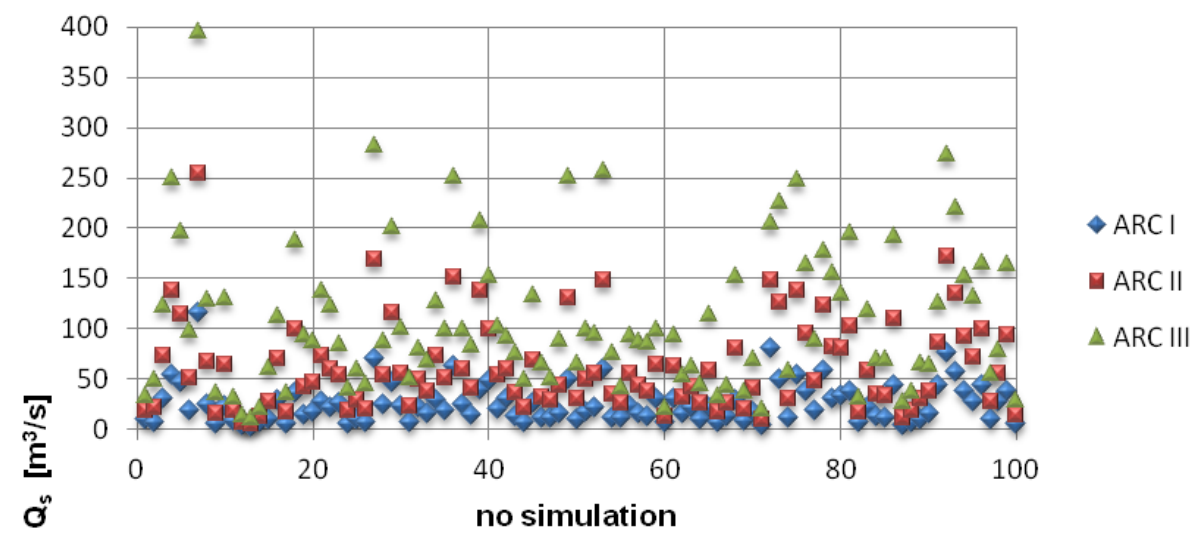

Fig. 8. Synthetic peak discharge values $Q_{s}$ for three types of ARC.

\subsection{An analysis of compatibility of the synthetic probability distributions of $\boldsymbol{Q}_{\text {sci }}$ and the probability distribution of observed $\boldsymbol{Q}_{o}$}

The created combinations $Q_{\text {sci }}$ were tested for goodness-of-fit to the theoretical probability distribution for the observed data $Q_{o}$. The goodness-of-fit of 
Table 4

Test statistic values for the Kolmogorov-Smirnov (K-S), Anderson-Darling (A-D), and Pearson $\left(\chi^{2} \mathrm{P}\right)$ goodness-of-fit tests

calculated for thirty-eight 100 -element combinations of synthetic $Q_{\text {sci }}$

\begin{tabular}{|c|c|c|c|c|c|c|c|}
\hline$i$ & \begin{tabular}{|}
$Q_{\text {sci }}$ combinations \\
where $i=1, \ldots, 38$
\end{tabular} & $\mathrm{~K}-\mathrm{S}$ & $\mathrm{K}-\mathrm{S}_{\text {crit. }}$ & A-D & A-D $D_{\text {crit. }}$ & $\chi^{2} \mathrm{P}$ & $\chi_{\text {crit. }}^{2}$ \\
\hline 1 & $1-0-0$ & 2.49 & \multirow{38}{*}{1.36} & 26.17 & \multirow{38}{*}{2.50} & 61.60 & \multirow{38}{*}{16.92} \\
\hline 2 & $0-1-0$ & 2.85 & & 16.74 & & 46.80 & \\
\hline 3 & 0-0-1 & 5.66 & & 101.25 & & 312.40 & \\
\hline 4 & 1-1-0 & 1.06 & & 4.16 & & 17.80 & \\
\hline 5 & $1-0-1$ & 4.35 & & 15.11 & & 74.60 & \\
\hline 6 & 0-1-1 & 2.36 & & 46.86 & & 131.40 & \\
\hline 7 & $0-1-2$ & 4.55 & & 53.81 & & 173.20 & \\
\hline 8 & $0-2-1$ & 3.35 & & 25.82 & & 63.80 & \\
\hline 9 & $1-0-2$ & 3.35 & & 29.03 & & 133.00 & \\
\hline 10 & 1-1-1 & 2.11 & & 11.68 & & 45.00 & \\
\hline 11 & $1-2-0$ & 1.25 & & 3.00 & & 14.60 & \\
\hline 12 & 2-0-1 & 1.49 & & 9.05 & & 38.80 & \\
\hline 13 & $2-1-0$ & 1.97 & & 12.27 & & 31.80 & \\
\hline 14 & $0-1-3$ & 4.68 & & 60.85 & & 190.40 & \\
\hline 15 & 0-3-1 & 3.05 & & 21.75 & & 53.60 & \\
\hline 16 & $1-0-3$ & 3.76 & & 40.20 & & 160.60 & \\
\hline 17 & 1-1-2 & 3.15 & & 24.28 & & 92.00 & \\
\hline 18 & $1-2-1$ & 2.15 & & 10.61 & & 34.40 & \\
\hline 19 & $1-3-0$ & 1.55 & & 4.15 & & 15.60 & \\
\hline 20 & 2-1-1 & 1.25 & & 6.96 & & 25.60 & \\
\hline 21 & $3-0-1$ & 1.79 & & 11.66 & & 40.60 & \\
\hline 22 & $3-1-0$ & 2.17 & & 16.72 & & 42.40 & \\
\hline 23 & $0-1-4$ & 4.96 & & 71.79 & & 234.60 & \\
\hline 24 & $0-2-3$ & 4.75 & & 57.37 & & 182.20 & \\
\hline 25 & $0-3-2$ & 3.85 & & 37.32 & & 98.80 & \\
\hline 26 & $0-4-1$ & 3.05 & & 21.85 & & 57.80 & \\
\hline 27 & $1-0-4$ & 4.26 & & 53.72 & & 204.00 & \\
\hline 28 & $1-1-3$ & 3.78 & & 35.23 & & 144.20 & \\
\hline 29 & $1-2-2$ & 3.15 & & 25.44 & & 85.60 & \\
\hline 30 & $1-3-1$ & 2.25 & & 10.13 & & 30.60 & \\
\hline 31 & $1-4-0$ & 1.95 & & 6.65 & & 23.40 & \\
\hline 32 & $2-0-3$ & 3.15 & & 24.61 & & 117.00 & \\
\hline 33 & $2-1-2$ & 2.35 & & 14.66 & & 59.80 & \\
\hline 34 & $2-2-1$ & 1.61 & & 7.11 & & 25.00 & \\
\hline 35 & $2-3-0$ & 1.21 & & 2.99 & & 15.60 & \\
\hline 36 & $3-0-2$ & 1.86 & & 10.53 & & 53.60 & \\
\hline 37 & $3-1-1$ & 1.44 & & 9.32 & & 28.80 & \\
\hline 38 & $3-2-0$ & 1.37 & & 7.38 & & 24.40 & \\
\hline
\end{tabular}

Note: grey colour means that test did not reject the combination. 

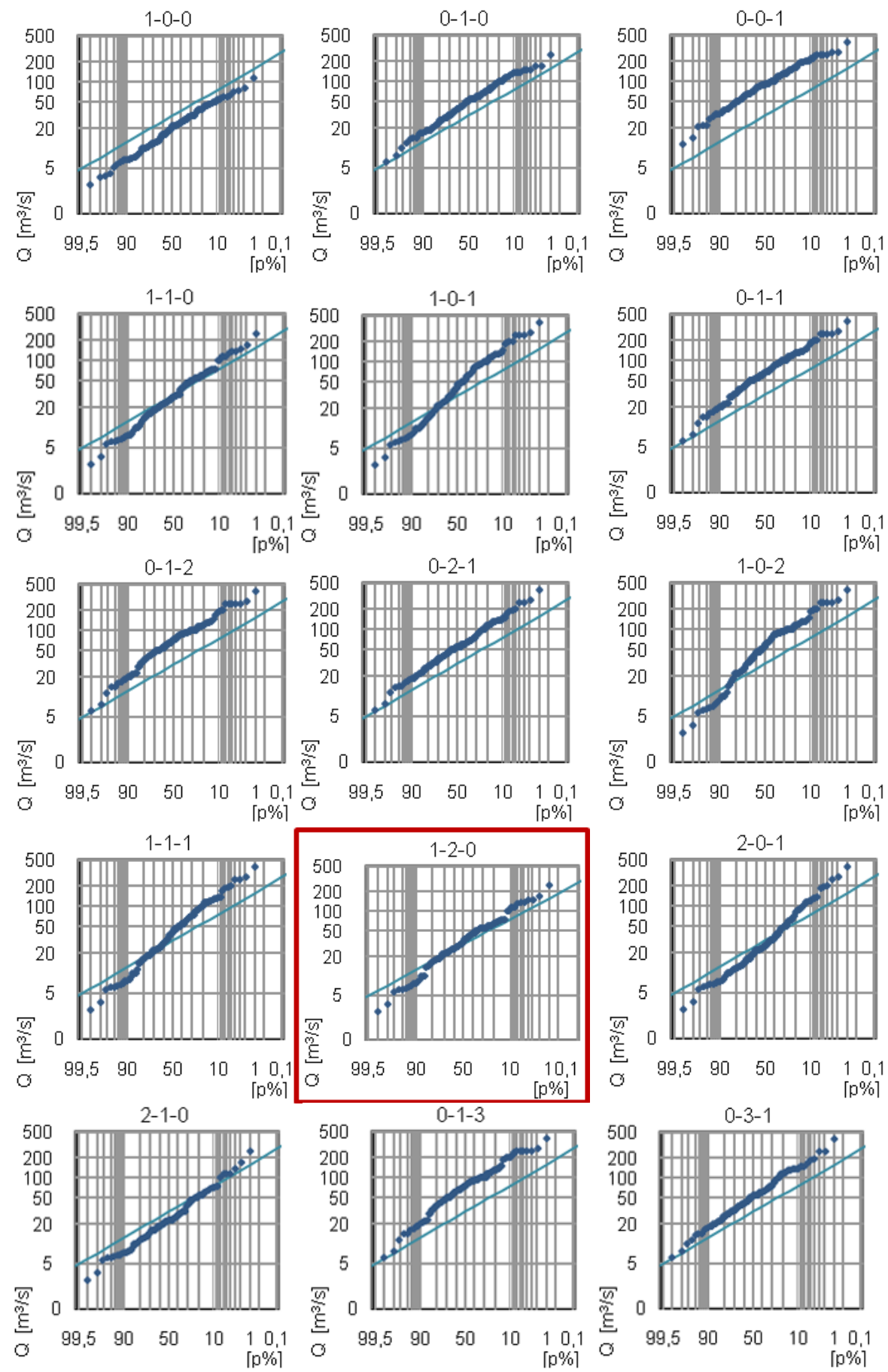

Fig. 9. Continued on next page. 

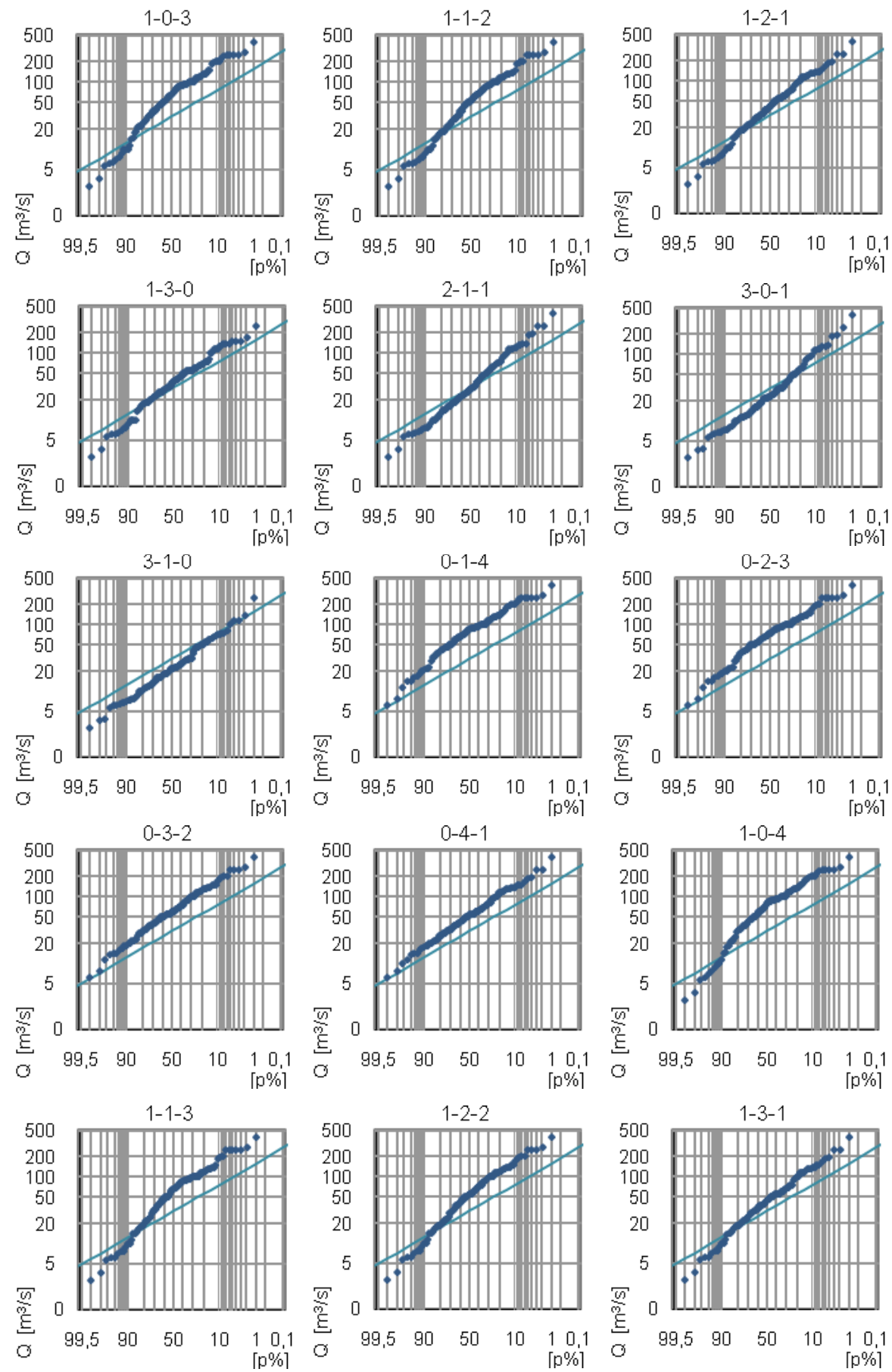

Fig. 9. Continued on next page. 

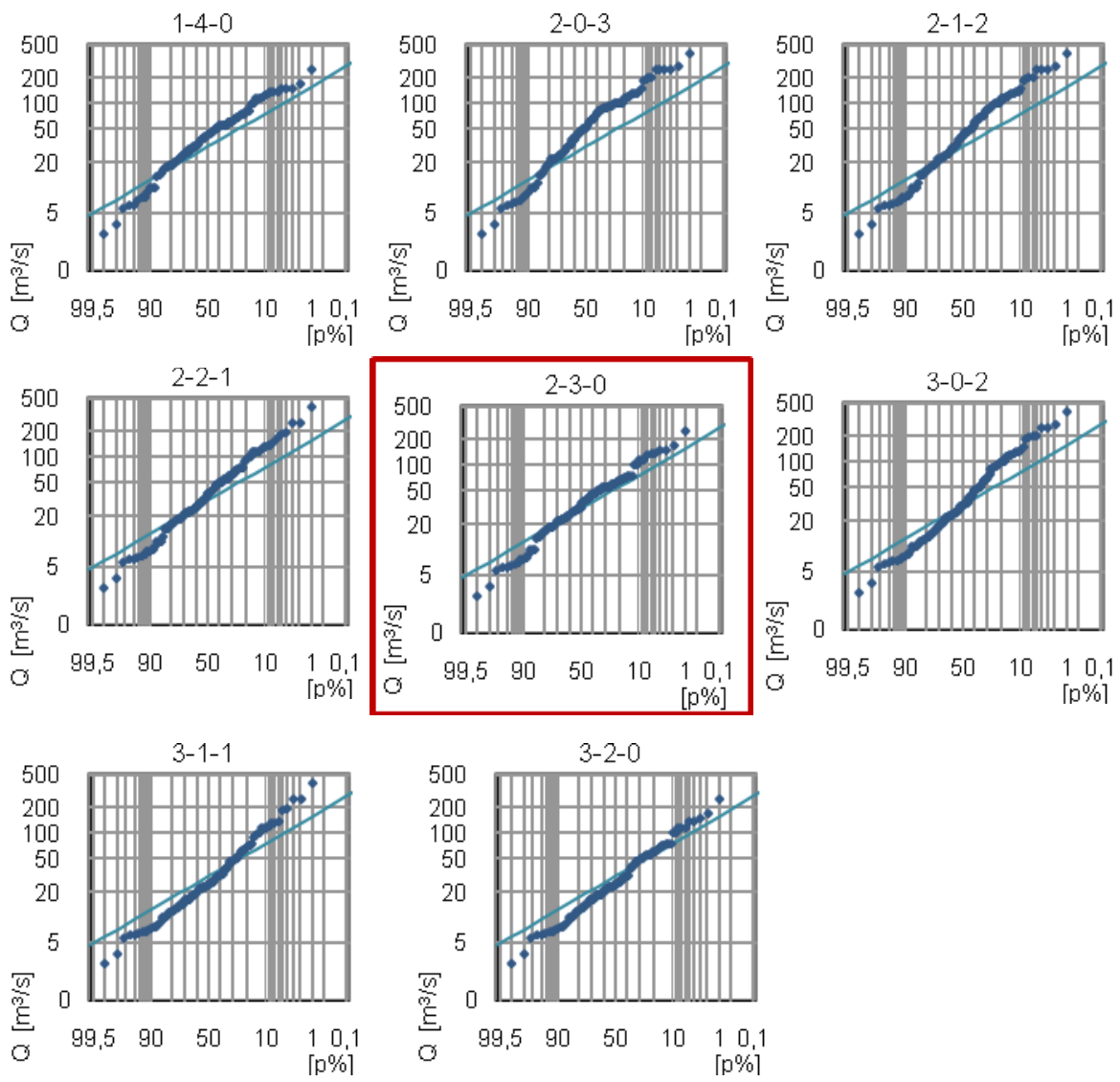

Fig. 9. Combinations of probability exceedance function of synthetic $Q_{\text {sci }}$ (full circles) and observed discharges $Q_{o}$ (solid line) at Polana cross-section in the Czarny catchment for different ARC. Combinations not rejected by the two tests are marked by framing.

both distributions was assessed using three tests: Kolmogorov-Smirnov (K-S), Anderson-Darling (A-D), and Pearson $\chi^{2}\left(\chi^{2} \mathrm{P}\right)$ (Table 4), under an assumption that the compatibility of distributions for a given combination must be not rejected by at least two tests.

The results of the K-S test did not reject the compatibility of both distributions in four cases, for the combinations: 1-1-0, 1-2-0, 2-1-1, 2-3-0, the $\chi^{2} \mathrm{P}-$ in three cases for the combinations: 1-2-0, 1-3-0, 2-3-0, while the A-D test rejected the compatibility for all the combinations. In consequence, there were two tests $\left(\mathrm{K}-\mathrm{S}\right.$ and $\left.\chi^{2} \mathrm{P}\right)$ that did not reject the compatibility of both distributions in only two cases, for the combinations: 1-2-0 and $\mathbf{2 - 3 - 0}$ (Fig. 9). 
An analysis of the basic combination types 1-0-0, 0-1-0, and 0-0-1 which represent discharge series from dry, normal, and wet conditions, respectively, did not reveal that it was only one of those conditions that would bear the greatest similarity to the observed data (Fig. 9). This finding was also confirmed by the K-S, A-D, and $\chi^{2} \mathrm{P}$ tests, whose statistic values for 1-0-0 are 2.49, 26.74, 61.60, for $\mathbf{0 - 1 - 0}$ are 2.85, 16.74, 46.80, and for $\mathbf{0 - 0 - 1}$ are 5.66, $101.25,312.40$, respectively, and which significantly exceed the critical test values: $1.36,2.50$, and 16.92 , respectively. In the case of combinations 1-2-0 and 2-3-0, for which the goodness-of-fit of both distributions was not reject by at least two tests, the statistic values are much lower than the critical values, and they are: $1.25(\mathrm{~K}-\mathrm{S})$, and $14.6\left(\chi^{2} \mathrm{P}\right)$ for 1-2-0, and $1.21(\mathrm{~K}-\mathrm{S})$, and15.6 $\left(\chi^{2} \mathrm{P}\right)$ for $\mathbf{2 - 3 - 0}$, respectively. However, compatibility of distributions of these combinations were rejected by the A-D test, but their statistic values are not much greater than the critical test values at the significance level alpha $=0.05$.

Based on the test of statistic values it can be concluded that the synthetic discharge values in proportions 1-2-0 and 2-3-0 of the ARC conditions in the river Czarny catchment demonstrate the best compatibility with the observed data.

In these optimal combinations, the synthetic discharge values come from only dry (from 33 to $40 \%$ ) and normal (from 60 to $67 \%$ ) antecedent conditions in the catchment. Wet antecedent runoff conditions (ARC III) do not affect the synthetic discharge values.

\section{ESTIMATING PROBABILITY DISTRIBUTION OF SYNTHETIC $Q_{s}$ FOR THE BEST ARC}

For two specific best proportions of antecedent runoff conditions ARC (1-2-0 and 2-3-0), estimated for the Czarny catchment in the Polana crosssection, discharge exceedance probability curves of $Q_{s}$ were created. At the same time, in order to increase the credibility of the flood quantiles from the probability distribution for very small exceedance probability, the modelling was performed on a 10000 -element rainfall sample. Then, 10000 synthetic values of $P_{s}$ from the identified probability distribution and 10000 pairs of parameters $\alpha$ and $\beta$ from their two-dimensional frequency distribution were generated, so that for every one rainfall value there is one pair of $(\alpha, \beta)$ parameters. This way, there were 10000 hyetographs with an hourly time step created by disaggregation of synthetic $P_{s}$, which were the input data for the rainfall-runoff model. In the process of modelling, there were three 10000 element series of peak discharges for three kinds of ARC obtained, which were further mixed in proportions 1-2-0 and 2-3-0, thus creating two 10000 element combinations $Q_{\text {sci. }}$. In consequence, for both combinations, probability distributions were estimated (Fig. 10). The values of synthetic flood 


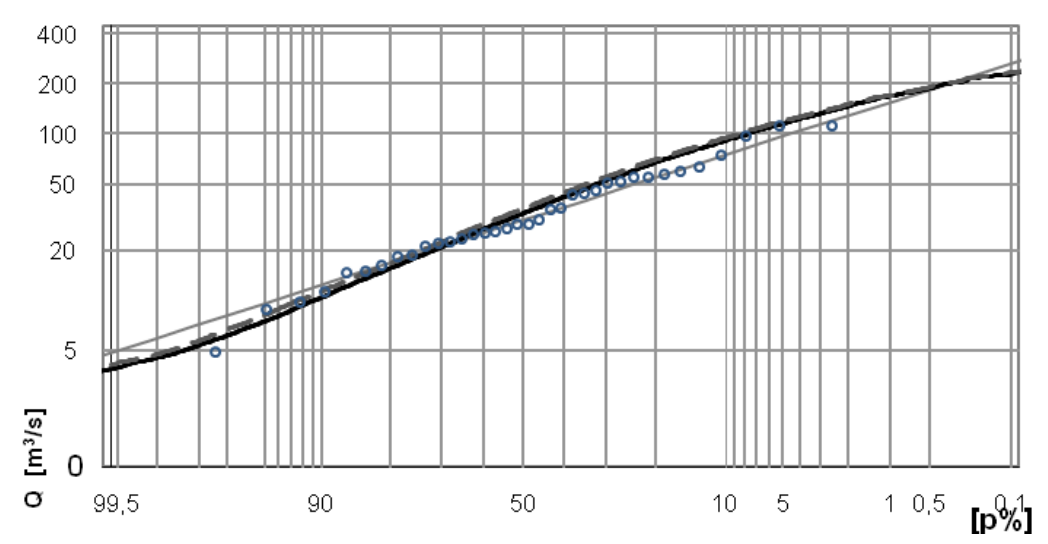

Fig. 10. Empirical (circles), theoretical (solid grey line), MESEF 1-2-0 (dotted line), and MESEF 2-3-0 (solid black line) flood quantiles for the Czarny catchment in the gauge station Polana.

quantiles for the asked probabilities $p$ were compared to the quantiles from the observed data.

\section{COMPARING FLOOD QUANTILES ESTIMATED USING THE MESEF AND THE CLASSICAL STATISTICAL METHOD}

In order to verify the efficiency of the proposed method, it was necessary to compare the flood quantiles $Q_{p}$ estimated using the MESEF and the classical statistical method (SM). SM is a direct method, common in Poland, used in controlled catchments and based on the observed values of maximum discharges $Q_{o}$. A comparison was carried out for two combinations: 1-2-0 and 2-3-0 (Table 5).

As it can be observed, in case of both combinations, the flood quantiles estimated using the MESEF method reveal slightly higher values than those estimated using the statistical method (for $p \geq 0.5 \%$ ). Only for $p=0.1 \%$ the flood quantile estimated using the MESEF method is slightly lower than the quantile estimated using the statistical method (SM).

What is more, relative errors of flood quantiles for the 1-2-0 and 2-3-0 combinations were calculated in order to find out which of the established proportions of antecedent moisture conditions ARC would bear the greatest similarity to the observed discharges. It can be observed here that for the 2-3-0 proportion, the relative error - in almost all of the cases, except for the $p=0.1 \%$ - reveals lower values than for the 1-2-0 proportion. It can be inferred from this information that the peak discharge probability distribution was most similar to the discharges for the $\mathbf{2 - 3 - 0}$ proportion of antecedent runoff conditions ARC. 
Table 5

Comparison of flood quantiles estimated using the statistical method (SM) and the MESEF method for two combinations: 1-2-0 and 2-3-0

\begin{tabular}{|c|c|c|c|c|c|c|c|}
\hline $\begin{array}{c}p \\
{[\%]}\end{array}$ & $\begin{array}{c}Q_{p} \\
(\mathrm{SM}) \\
{\left[\mathrm{m}^{3} / \mathrm{s}\right]}\end{array}$ & $\begin{array}{c}Q_{p(1-2-0)} \\
(\mathrm{MESEF}) \\
{\left[\mathrm{m}^{3} / \mathrm{s}\right]} \\
\end{array}$ & $\begin{array}{c}Q_{p(2-3-0)} \\
(\mathrm{MESEF}) \\
{\left[\mathrm{m}^{3} / \mathrm{s}\right]} \\
\end{array}$ & $\begin{array}{c}\text { Difference } \\
\Delta_{1}^{\mathrm{a})} \\
(1-2-0) \\
{\left[\mathrm{m}^{3} / \mathrm{s}\right]} \\
\end{array}$ & $\begin{array}{c}\text { Difference } \\
\Delta_{2}^{\mathrm{b})} \\
(2-3-0) \\
{\left[\mathrm{m}^{3} / \mathrm{s}\right]}\end{array}$ & $\begin{array}{c}\text { Relative } \\
\text { error } \delta_{1}^{\mathrm{c})} \\
(1-2-0) \\
{[\%]}\end{array}$ & $\begin{array}{c}\text { Relative } \\
\left.\text { error } \delta_{2}{ }^{\mathrm{d}}\right) \\
(2-3-0) \\
{[\%]}\end{array}$ \\
\hline 0.1 & 242.0 & 236.7 & 236.0 & 5.4 & 6.0 & 2.2 & 2.5 \\
\hline 0.5 & 190.2 & 196.7 & 191.8 & -6.4 & -1.5 & 3.4 & 0.8 \\
\hline 1 & 147.2 & 173.7 & 170.4 & -26.5 & -23.2 & 18.0 & 15.7 \\
\hline 2 & 123.2 & 153.1 & 148.8 & -29.9 & -25.7 & 24.3 & 20.9 \\
\hline 5 & 94.1 & 120.5 & 117.0 & -26.4 & -22.9 & 28.0 & 24.3 \\
\hline 10 & 74.0 & 95.4 & 92.2 & -21.4 & -18.2 & 28.9 & 24.6 \\
\hline 20 & 55.2 & 70.7 & 67.9 & -15.5 & -12.7 & 28.1 & 23.0 \\
\hline 30 & 44.5 & 55.2 & 52.7 & -10.7 & -8.2 & 24.0 & 18.4 \\
\hline 50 & 31.1 & 35.4 & 33.3 & -4.4 & -2.2 & 14.0 & 7.1 \\
\hline
\end{tabular}

${ }^{\text {a) }} \Delta_{1}=Q_{p}(\mathrm{SM})-Q_{p(1-2-0)}(\mathrm{MESEF}),{ }^{\mathrm{b})} \Delta_{2}=Q_{p}(\mathrm{SM})-Q_{p(2-3-0)}(\mathrm{MESEF})$, ${ }^{\text {c) }} \delta_{1}=\Delta_{1} / Q_{p}(\mathrm{SM}) \times 100 \%,{ }^{\text {d) }} \delta_{2}=\Delta_{2} / Q_{p}(\mathrm{SM}) \times 100 \%$.

Table 6

Comparison of flood quantiles estimated using classical methods: statistical (SM) and area regression equation (RE)

\begin{tabular}{|c|c|c|c|c|}
\hline $\begin{array}{c}p \\
{[\%]}\end{array}$ & $\begin{array}{c}Q_{p}(\mathrm{SM}) \\
{\left[\mathrm{m}^{3} / \mathrm{s}\right]}\end{array}$ & $\begin{array}{c}Q_{p}(\mathrm{RE}) \\
{\left[\mathrm{m}^{3} / \mathrm{s}\right]}\end{array}$ & $\begin{array}{c}\text { Difference } \Delta_{3}{ }^{\mathrm{a})} \\
{\left[\mathrm{m}^{3} / \mathrm{s}\right]}\end{array}$ & $\begin{array}{c}\text { Relative error } \delta_{3}{ }^{\mathrm{b}} \text { ) } \\
{[\%]}\end{array}$ \\
\hline 0.1 & 242.0 & 149.4 & 92.7 & 38.3 \\
0.5 & 190.2 & 117.0 & 73.2 & 38.5 \\
1 & 147.2 & 102.3 & 44.9 & 30.5 \\
2 & 123.2 & 88.0 & 35.2 & 28.6 \\
5 & 94.1 & 69.0 & 25.1 & 26.7 \\
10 & 74.0 & 54.8 & 19.2 & 25.9 \\
20 & 55.2 & 40.0 & 15.2 & 27.5 \\
30 & 44.5 & 32.0 & 12.5 & 28.1 \\
50 & 31.1 & 16.5 & 14.6 & 47.0 \\
\hline
\end{tabular}

${ }^{\text {a) }} \Delta_{3}=Q_{p}(\mathrm{SM})-Q_{p}(\mathrm{RE}),{ }^{\text {b) }} \delta_{3}=\Delta_{3} / Q_{p}(\mathrm{SM}) \times 100 \%$.

Additionally, another method was verified that is widespread in use in Poland for estimating flood quantiles using the area regression equation (RE). RE is a method used in uncontrolled catchments with an area from 50 
to $2000 \mathrm{~km}^{2}$ (RZGW 2014). The true values used, similarly to the assessment of the MESEF method, were quantiles based on observed data obtained from the SM method (Table 6).

The flood quantiles obtained using the regression equation (RE) reveal significantly lower values than the quantiles obtained using the statistical method (SM) for all cases. This is confirmed by the calculated values of the relative error. The highest significant relative error applies to flood quantiles with a $p=50 \%$ exceedance probability and it is $47 \%$. The obtained results show limitations of the RE method; therefore, the proposed MESEF method could prove to be a good alternative.

\section{CONCLUSION AND PERSPECTIVES}

The article presents a new approach to estimating flood quantiles based on rainfall-runoff modelling using multiple rainfall events. This approach is a new idea in a practical application in Poland, including: applying rainfall generator, disaggregation of rainfall by generating parameters $\alpha$ and $\beta$ of the beta distribution $\operatorname{Be}(\alpha, \beta)$, as well as discharge modelling that considers different catchment antecedent runoff conditions ARC. The proposed MESEF method was applied in a natural catchment of the Czarny River, in a crosssection Polana. The values of flood quantiles obtained from the MESEF method are similar to the quantiles obtained using the statistical method (SM), and are burdened with smaller error than the quantiles estimated using the regression equation (RE). This means that they are of good similarity to the discharges from observed data.

It can be concluded that the new approach, which is based on generated precipitation and considers catchment antecedent runoff conditions ARC, marks a good direction to estimating flood quantiles in small catchments to $100 \mathrm{~km}^{2}$. It is interesting whether the same proportion of ARC would be confirmed in other catchments. Further research in this area might produce valuable information.

Finding new methods for estimating flood quantiles is important, especially in the context of considering changes in both climate and catchment planning - the new factors influencing floods. What is more, the obtained flood quantiles are based on many rainfall events rather than a single one, as opposed to the currently used classical design event method. In result, flood distributions obtained by rainfall modelling make it possible to analyse the efficiency of technical and non-technical flood control methods in both gauged and ungauged catchments.

It should be noted here that the applicability of the MESEF method needs to be additionally tested in different catchments, and the authors would like to elaborate on the problem in their future publications as part of the on-going research. 
Acknowledgements. We would like to thank the reviewers for valuable comments that greatly improved the paper.

\section{References}

Banasik, K. (2009), Determining of Flood-swelling in Small Urban Catchments, Warsaw University of Life Sciences Press, Warsaw, 42 pp. (in Polish).

Boughton, W., and O. Droop (2003), Continuous simulation for design flood estimation - a review, Environ. Modell. Softw. 18, 4, 309-318, DOI: 10.1016/ S1364-8152(03)00004-5.

Calver, A., and R. Lamb (1995), Flood frequency estimation using continuous rainfall-runoff modelling, Phys. Chem. Earth 20, 5-6, 479-483, DOI: 10.1016/ S0079-1946(96)00010-9.

Cameron, D.S., K.J. Beven, J. Tawn, S. Blazkova, and P. Naden (1999), Flood frequency estimation by continuous simulation for a gauged upland catchment (with uncertainty), J. Hydrol. 219, 3-4, 169-187, DOI: 10.1016/S00221694(99)00057-8.

DVWK (1984), Arbeitsanleitung zur Anwedung von Niederschlag-Abfluss Modellen in kleinen Einzugsgebieten, Teil II: Synthese, Deutscher Verband für Wasserwirtschaft und Kulturbau, Vol. 113, Paul Parey Verlag, Hamburg (in German).

Francés, F., R. García-Bartual, E. Ortiz, S. Salazar, J. Miralles, G. Blöschl, J. Komma, C. Habereder, A. Bronstert, and T. Blume (2008), CRUE Research Report No. I-6: Efficiency of non-structural flood mitigation measures: "room for the river" and "retaining water in the landscape", CRUE Funding Initiative on Flood Risk Management Research, London, 172-213.

Hawkins, R.H., T.J. Ward, D.E. Woodward, and J.A. van Mullem (eds.) (2009), Curve Number Hydrology: State of the Practice, ASCE/EWRI Curve Number Hydrology Task Committee, American Society of Civil Engineers. Reston, DOI: 10.1061/9780784410042.

Kowalczak, P. (2011), Climate variability and the causes of the floods in Poland, Institute for Agricultural and Forest Environment, Polish Academy of Sciences, Poznań, Poland, http://www.umweltaktion.de/pics/medien/ 1_1324305988/Vortrag_Kowalczak.pdf (in Polish).

KPZK 2030 (2012), National Spatial Development Concept 2030, Monitor Polski, Warszawa, 27.04.2012, Poz. 252 (in Polish).

Lee, K.T., and J.K. Huang (2013), Runoff simulation considering time-varying partial contributing area based on current precipitation index, J. Hydrol. 486, 443-454, DOI: 10.1016/j.jhydrol.2013.02.016. 
Licznar, P. (2009), Generators of Synthetic Rain Rows for Modelling of the Stormwater Drainage and Combined Sewage Systems, Wrocław University of Environmental and Life Sciences Publ., Wrocław, 180 pp. (in Polish).

Mishra, S.K., and V.P. Singh (2003), Soil Conservation Service Curve Number (SCS-CN) Methodology, Water Science and Technology Library, Vol. 42, Kluwer Academic Publishers, Dordrecht, 519 pp.

Nowicka, B., U. Soczyńska, and U. Somorowska (1997), Prediction of the design floods frequency. In: U. Soczyńska (ed.), Prediction of the Design Storms and Floods, University of Warsaw Publisher, Warsaw, 143-177 (in Polish).

Osuch, M., R.J. Romanowicz, E. Paquet, and F. Garavaglia (2013), Application of the SCHADEX method to estimate annual maximum flow of given exceedance probability of the Nysa Kłodzka river. In: S. Weglarczyk (ed.), The Problems of Calculating Extreme Discharge in Controlled and Uncontrolled Catchments, Monographs of Committee of Environmental Engineering PAS, Vol. 35, 73-86 (in Polish).

Paquet, E., F. Garavaglia, R. Garçon, and J. Gailhard (2013), The SCHADEX method: A semi-continuous rainfall-runoff simulation for extreme flood estimation, J. Hydrol. 495, 23-37, DOI: 10.1016/j.jhydrol.2013.04.045.

Pathiraja, S., S. Westra, and A. Sharma (2012), Why continuous simulation? The role of antecedent moisture in design flood estimation, Water Resour. Res. 48, 6, W0653, DOI: 10.1029/2011WR010997.

Pilgrim, D.H., and I. Cordery (1993), Flood runoff. In: D.R. Maidment (ed.), Handbook of Hydrology, McGraw-Hill Inc., New York, 9.1-9.42.

Rahman, A., P.E. Weinmann, T.M.T. Hoang, and E.M. Laurenson (2002), Monte Carlo simulation of flood frequency curves from rainfall, J. Hydrol. 256, 34, 196-210, DOI: 10.1016/S0022-1694(01)00533-9.

RZGW (2014), Regulation no. 4/2014 of Director of Regional Water Management Board in Kraków (the RZGW in Kraków) of 16 January 2014 on conditions to use water of Górna Wisła water region, Regionalny Zarząd Gospodarki Wodnej, Kraków, Poland, http://bip.malopolska.pl/rzgwkrakow/Article/ get/id,848610.html (in Polish).

Scharffenberg, W., and M. Fleming (2010), Hydrologic modeling system HECHMS v.3.5 user's manual, U.S. Army Corps of Engineers, Davis, USA.

SPA 2020 (2013), Polish National Strategy for Adaptation to Climate Change (SPA 2020), Ministry of Environment, Warszawa, Poland, http://klimada.mos. gov.pl/wp-content/uploads/2013/10/SPA2020.pdf (in Polish).

Stedinger, J.R., R.M. Vogel, and E. Foufoula-Georgiou (1993), Frequency analysis of extreme events. In: D.R. Maidment (ed.), Handbook of Hydrology, McGraw-Hill Inc., New York, 18.1-18.66.

USDA (1986), Urban hydrology for small watersheds, Technical Release No. 55, United States Department of Agriculture, U.S. Government Printing Office, Washington DC. 
Węglarczyk, S. (2010), Statistics in Environmental Engineering, Cracow University of Technology Publisher, Cracow (in Polish).

Więzik, B. (2010), Annual maximum discharges of given exceedance probability in small ungauged catchments. In: B. Więzik (ed.), Hydrology in Engineering and the Water Management, Monographs of Committee of Environmental Engineering PAS, Vol. 68, 153-165 (in Polish).

Received 13 Februray 2014 Received in revised form 5 July 2015

Accepted 30 July 2015 